\title{
COMPARISON OF EFFECTIVENESS OF LECTURE AND SEMINAR AS TEACHING-LEARNING METHODS IN PHYSIOLOGY WITH RESPECT TO COGNITIVE GAIN AND STUDENT SATISFACTION
}

\author{
Pradeep C. Thomas ${ }^{1}$, Radha T. R2, Subitha $K^{3}$, Geethadevi $M^{4}$ \\ ${ }^{1}$ Associate Professor, Department of Physiology, Government Medical College, Kottayam. \\ ${ }^{2}$ Additional Professor, Department of General Medicine \& Medical Education, Co-convenor of Medical Council of India, Nodal Centre for \\ Faculty Development, Government Medical College, Kottayam. \\ ${ }^{3}$ Associate Professor (CAP), Department of Pathology \& Medical Education, MCINCFD, Govt. Medical College, Kottayam. \\ ${ }^{4}$ Associate Professor (CAP), Department of Community Medicine \& Medical Education, MCINCFD, Government Medical College, \\ Kottayam.
}

\section{ABSTRACT}

\section{BACKGROUND}

Lecture is the usual method of teaching Physiology theory to first year MBBS students. Seminar hours are fewer. Some studies from other institutions have reported that cognitive gain produced was greater by seminar than by lecture. Therefore, we conducted a research to check whether this is true regarding the students in our institution. We aimed to compare the cognitive gain in Physiology produced by Lecture and Seminar and to compare the student satisfaction produced by Lecture and Seminar.

\section{MATERIALS AND METHODS}

We conducted an interventional (Experimental) study in Government Medical College, Idukki to evaluate the effectiveness of lecture and seminar as teaching-learning methods in Physiology in first year MBBS students. All the 50 students in the college gave consent for the study; and were assorted randomly by lottery method to 2 groups. One group was subjected to lecture on coronary circulation and then seminar on cerebral circulation. The other group was subjected to lecture on cerebral circulation and then seminar on coronary circulation. The same person did all the interventions. For seminar, students in each group were assorted randomly by lottery method into 3 subgroups of 8-9 students to allow enough opportunity for each student to actively discuss the topic. The level of knowledge on the topic was assessed before and immediately after each intervention using the same set of single response Multiple Choice Questions; and cognitive gain was calculated as Post-test mark minus Pre-test mark. Student satisfaction was assessed immediately after each intervention by the same student perception feedback questionnaire in Likert scale. Data was analysed using the software SPSS version 21 . The cognitive gains by lecture and seminar were compared using Independent samples t-test. $\chi^{2}$-test was used to check statistical significance of the feedback responses.

Design- Randomised Controlled Trial of teaching-learning methods with cross-over type of study design.

\section{RESULTS}

Lecture and seminar produced statistically significant improvements in the test scores. The cognitive gain produced was more by lecture than by seminar, but the difference was not statistically significant. Students reported greater satisfaction by seminar than by lecture.

\section{CONCLUSION}

Lecture as well as seminar is effective in increasing the knowledge of MBBS students in Physiology; but each method has its own relative merits. So, both these methods shall be used in teaching Physiology to avail the advantages of both.

\section{KEYWORDS}

Lecture, Seminar, Cognitive Gain, Student Satisfaction.

HOW TO CITE THIS ARTICLE: Thomas PC, Radha TR, Subitha K, et al. Comparison of effectiveness of lecture and seminar as teaching-learning methods in Physiology with respect to cognitive gain and student satisfaction. J. Evolution Med. Dent. Sci. 2017;6(59):4357-4362, DOI: 10.14260/Jemds/2017/942

\section{BACKGROUND \\ Lecture is the usual method of teaching Physiology theory.} Since 2 decades, a few hours of seminar have also been included in physiology curriculum.

Financial or Other, Competing Interest: None.

Submission 16-06-2017, Peer Review 12-07-2017,

Acceptance 17-07-2017, Published 24-07-2017.

Corresponding Author:

Dr. Pradeep C. Thomas,

Associate Professor,

Department of Physiology,

Government Medical College,

Gandhinagar P. O., Kottayam-686008,

Kerala.

E-mail: pradeepcthomas@gmail.com

DOI: $10.14260 /$ jemds $/ 2017 / 942$

\section{(c) $(1) \ominus$}

Lecture is a large group teaching method. Traditional didactic lecture involves mainly passive learning by the students of the knowledge orally communicated by the teacher, with or without audio-visual aids. Seminar is a small group teaching method in which a group of students actively learn under the guidance of a teacher by discussing among themselves a topic which each one knows to a different extent, while the teacher serves only as a facilitator, with the least intervention possible.

There were some study reports that cognitive gain produced in MBBS students for certain medical topics are greater by small group teaching methods involving active learning than by large group teaching methods involving mainly passive learning. ${ }^{\mathbf{1 , 2 , 3}}$ But there were no such studies from Govt. Medical College, Idukki, where the first author was working during the study. 
The present project intended to check whether this is true with respect to Physiology in students of that institution. The results of this study were expected to suggest whether more of the Physiology theory needs to be covered by seminars for more effective teaching \& learning.

\section{Objectives}

1. To compare the cognitive gain in Physiology (in selected topics) produced by Lecture and Seminar.

2. To compare the student satisfaction produced by Lecture and Seminar.

\section{MATERIALS \& METHODS \\ Study Design}

Randomised Controlled Trial of teaching-learning methods with cross-over type of study design. For teaching a particular topic the students were randomly allocated to a study group which was taught by seminar and a control group which was taught by lecture. Then the 2 groups are switched. For another but similar topic, the former group was changed to control group taught by lecture and the latter group was changed to study group taught by lecture.

\section{Period of Study}

July 2015- December 2015 i.e. 6 months.

\section{Subjects/Sample Size}

The study group comprised of all the 50 first year MBBS students of 2014-2015 regular batch of Govt. Medical College, Idukki, who gave consent for the study. Two subgroups of 25 each was constituted by random allocation by lottery method from the study group of 50 students.

\section{The Subgroups were-}

- H group which had coronary circulation as seminar topic.

- B group which had brain circulation as seminar topic.

A study group of 50 students was chosen to meet the minimum sample size of 30 required for statistical significance. The study group was divided into subgroups because, seminar, being a small group teaching-learning method, cannot have $>30$ students at a time. Though all the 50 students attended lecture, 7 ( 4 from group ' $\mathrm{H}$ ' and 3 from group 'B') did not attend seminar as they were having fever. So, data collected from only the 43 students who attended both lecture and seminar were used for analysis.

\section{Inclusion Criteria}

1. First year MBBS students of Govt. Medical College, Idukki.

2. Students who were willing to give consent for the study.

\section{Exclusion criteria}

1. Students who did not give consent for the study.

2. Students who were absent from any session of the study.

The study was approved by the Institutional Ethics Committee of Govt. Medical College, Kottayam (IRB No: $76 / 2015$ dated $02 / 07 / 2015$ ) as there was no institutional ethics committee in the newly started Govt. Medical College, Idukki.

\section{Methodology}

All the 50 students who gave consent were included in the study. Allocation to the subgroups was by random sampling by lottery method.

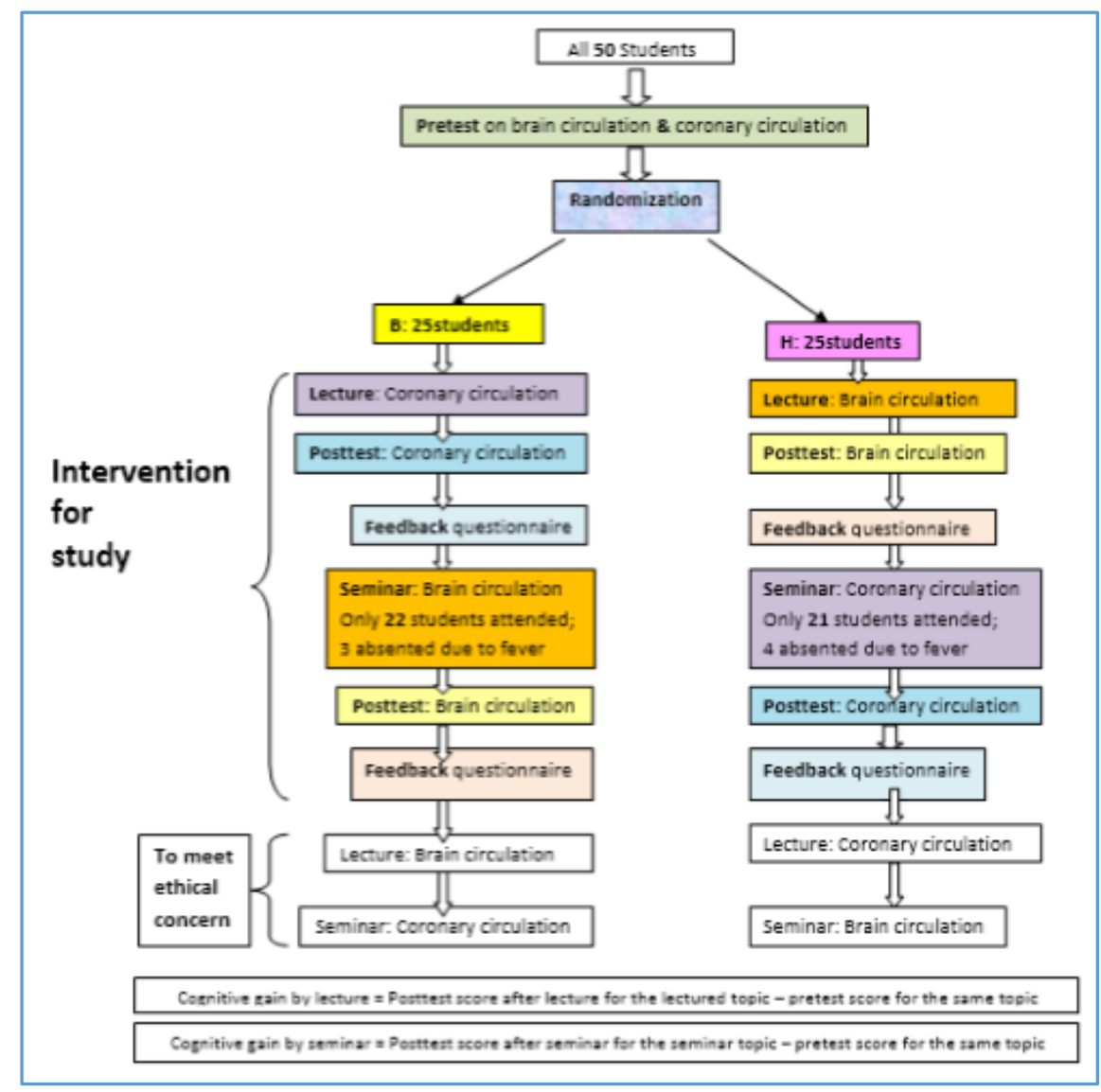


The whole batch of 50 First year MBBS students were informed about the present research and explained that the participants have to prepare for seminar and participate in discussions, their marks scored regarding the portions taught for research would be taken for research purpose without affecting internal assessment marks and that they have to give written feedback which will not affect them in any way. He then requested that only the fully willing students may give him the consent. Each student was requested to read, understand, and sign the consent form. The consent form had got approval from the Ethics Committee. All the 50 students gave their consent.

Immediately after getting consent, all the 50 students were given single response type MCQ Pre-tests, each student taking 2 tests, one on brain circulation and the other on coronary circulation. The answers were got on question paper itself and all the question papers were taken back from the students before they left the examination hall to avoid leaking of questions. No hint was given that the same questions would be given for Post-test; but on each topic, the same questions were used for Post-test after each intervention using either lecture or seminar.

The whole batch of 50 students was divided into 2 groups of 25 each by lottery method of randomly assorting each student to one group or the other. Steps were taken to ensure equal chance for each participant to get allocated to each group. 50 identical white papers, 25 of them with the letter ' $\mathrm{B}$ ' inscribed on one side and the other 25 with the letter ' $\mathrm{H}$ ' inscribed on one side, were folded into identically looking pieces to conceal the inscribed letters and were shut up in a box, and then shaken in many directions many times. Students were requested to meet the first author during each one's convenient time during a day. Students came singly, and in groups, in no recognisable order, at their own conveniences and when each student met, the lid of the box was removed and the student was requested to dip a hand into the box and pick up any one of the folded paper pieces and hand over it without unfolding to the first author. The first author unfolded the paper and noted the letter on the paper against the name of the student who picked it. All the 50 students came and picked lots. The list of students with the letter each one got was announced and put up in the Physiology Department noticeboard. The students who got $\mathrm{H}$ were requested to individually study 'Coronary Circulation' to the extent that each one shall be confident to present the whole topic without any aids to the whole class 2 weeks later and actively discuss the topic. Those who got 'B' were requested to prepare with 'Cerebral Circulation' as detailed above. The responsibility for each student to teach others and to extract knowledge from others by actively participating in the discussions during the seminar was also convinced.

Steps were taken to ensure that students do not get chance to prepare for Pre-test, but get ample time to prepare for seminar. After the lecturing to each group separately on the topic not assigned to them for seminar, the groups were made to take Post-test on the topic lectured and answer the feedback questionnaire and was instructed, for research's sake, not to give their notes or speak to the members of the other group regarding questions asked and the content of the lecture. Only 43 students (21 from group ' $\mathrm{H}$ ' and 22 from group ' $B$ ') attended the seminars. 7 students ( 4 from group ' $\mathrm{H}$ ' and 3 from group ' $\mathrm{B}$ ') could not attend seminar because of fever. When each group came for seminar, it was subdivided into 3 small subgroups of 8-9 students to enable each student to get ample time to contribute to the discussions. Each student was randomly assorted to one of the 3 groups $(1,2$, or 3 ) by lottery method in the same way that the B and $\mathrm{H}$ groups were formed. After each group's seminar, students took the Post-test on the seminar topic followed by answering the feedback questionnaire.

\section{Intervention}

- Two topics of similar nature and similar complexitybrain circulation and coronary circulation, were taught by 2 different methods- lecture and seminar.

- Two weeks before the intervention, one group was asked to prepare for a seminar on brain circulation and the other group was asked to prepare for a seminar on coronary circulation.

- One group was lectured on coronary circulation and participated in seminar on brain circulation.

- The other group was lectured on brain circulation and later participated in seminar on coronary circulation.

- To avoid the ethical problem of deprivation of any group of students of any teaching-learning method on any of the topic included in the research, after the data collection for the research was over, each group was taught each of the topic on later dates by the method not used for research intervention.

\section{Study Tool}

1. Student perception feedback questionnaire in Likert scale.

2. Single-response type multiple choice questions.

\section{Data Collection}

- Before intervention, a pre-test consisting of singleresponse type multiple choice questions in 2 separate question papers - one consisting 10 questions on brain circulation and the other consisting 10 questions on coronary circulation, was given to both groups simultaneously.

- $\quad$ After 2 weeks, on the $1^{\text {st }}$ day of intervention, group B got a 2-hour lecture on coronary circulation conducted by the investigator followed by a post-test on coronary circulation using the same question paper set for pretest and then requested to fill a feedback questionnaire to assess their level of satisfaction by scoring system based on Likert scale.

- $\quad$ On the next day, group $\mathrm{H}$ got a 2-hour lecture on brain circulation conducted by the investigator followed by a post-test on brain circulation using the same question paper set for pre-test and then assessment of students' perception of the lecture using the same feedback questionnaire.

- $\quad$ On the eighth day, the 3 subgroups of group B separately participated in a 2-hour seminar (all the members of a subgroup sat in a round and discussed the topic) on brain circulation guided by the investigator (to facilitate discussion and ensure participation of each student) followed by a post-test on brain circulation using the same question paper set for pre-test and then the same feedback questionnaire to assess their level of satisfaction. 
- On the ninth day, group $\mathrm{H}$ participated in a 2-hour seminar on coronary circulation guided by the investigator followed by a post-test on coronary circulation using the same question paper set for pretest and then the same feedback questionnaire.

- The marks of each student for each paper were assessed separately.

- Cognitive gain for each student by seminar was taken as improvement in the post-test scores (group B - Post-test brain circulation score minus Pre-test brain circulation score; group H - Post-test coronary circulation score minus Pre-test coronary circulation score).

- Cognitive gain by lecture was also calculated similarly for each student. (Group B - Post-test coronary circulation score minus Pre-test coronary circulation score; group $\mathrm{H}$ - Post-test brain circulation score minus Pre-test brain circulation score).

\section{Statistical Analysis}

Statistical analysis was done using the software SPSS version 21. Mean of Pre-test scores and Post-test scores for lecture and seminar were compared using Paired samples t-test. Cognitive gain was calculated as Post-test score minus Pretest score. Mean cognitive gain of all the students by seminar and by lecture were compared using Independent samples ttest. Satisfaction of students was assessed from the filled feedback questionnaire by rating it using Likert scale and then analysing using frequency tables. $\chi^{2}$-test was used to check statistical significance of the feedback responses. For all statistical evaluations, probability of value $<0.05$ was considered significant.

\section{RESULTS}

\begin{tabular}{|c|c|c|c|}
\hline $\begin{array}{c}\text { Teaching-Learning } \\
\text { Method }\end{array}$ & & $\begin{array}{c}\text { Mean } \pm \text { Standard } \\
\text { deviation }\end{array}$ & $\begin{array}{c}\mathbf{p} \\
\text { value }\end{array}$ \\
\hline \multirow{2}{*}{ Lecture } & Pre-test & $1.86 \pm 1.146$ & \multirow{2}{*}{$0^{*}$} \\
\cline { 2 - 3 } & Post-test & $4.88 \pm 1.93$ & \\
\hline \multirow{2}{*}{ Seminar } & Pre-test & $2.98 \pm 1.596$ & \multirow{2}{*}{$0^{*}$} \\
\cline { 2 - 3 } & Post-test & $5.33 \pm 1.375$ & \\
\hline \multicolumn{2}{|c|}{ Marks gained by lecture } & $3.023 \pm 2.0294$ & \multirow{2}{*}{$0.087 \dagger$} \\
\hline \multicolumn{2}{|c|}{ Marks gained by seminar } & $2.349 \pm 1.5566$ & \\
\hline \multicolumn{2}{|c|}{ Table 1. Comparison of the Test scores } \\
\hline
\end{tabular}

*Paired t-test

†Independent samples t-test

\section{Comparison of Pre-test \& Post-test Marks in Lecture Topic}

The Post-test marks scored by the students after the lecture did not show statistically significant correlation $(\mathrm{p}>0.05)$ with their Pre-test marks. This indicates that some factor, other than the level of pre-existing knowledge on the topic, and which varies with the individual has influenced the cognitive gain by the individual students from lecture.

The mean of the marks scored after lecture was significantly greater $(\mathrm{p}<0.005)$ than the mean of the marks scored before lecture. This proves that lecture is effective in producing cognitive gain in students.

\section{Comparison of Pre-test \& Post-test Marks in Seminar}

The Post-test marks scored by the students after the seminar showed significant correlation $(\mathrm{p}<0.005)$ with their Pre-test marks. This indicates that the level of pre-existing knowledge on the topic is an important factor which determines the cognitive gain by the individual students from seminar.

The mean of the marks scored after seminar was significantly greater $(p<0.005)$ than that scored before seminar. This proves that seminar is effective in producing cognitive gain in students.

\section{Comparison of the Cognitive Gains by Lecture \& Seminar:} T-Test

The cognitive gain as measured in the gain in marks (Posttest mark - Pre-test mark) was more after lecture (3.023 \pm 2.0294) than after seminar $(2.349 \pm 1.5566)$, but the difference was not statistically significant $(\mathrm{p}>0.05)$.

\section{Students' Feedbacks on Lecture and Seminar}

$86.1 \%$ of students agreed that seminar evoked more interest in the topic; and of them, $41.9 \%$ strongly agreed. Only $53.5 \%$ of students agreed that lecture evoked more interest in the topic; and of them, only $2.3 \%$ strongly agreed. These data indicate that seminar is subjectively more effective than lecture in evoking interest in the topic.

$90.7 \%$ of students agreed that seminar helped to understand concepts better; and of them, 67.4\% strongly agreed. Only $72.1 \%$ of students agreed that lecture helped to understand concepts better; and of them, only $9.3 \%$ strongly agreed. These data indicate that seminar as well as lecture is effective in helping the students to understand concepts; but seminar is subjectively much more effective than in helping the students to understand concepts.

$93 \%$ of students agreed that seminar helped to clear doubts; and of them, 53.5\% strongly agreed. Only 53.5\% agreed that lecture helped to clear doubts; and of them, only $7 \%$ strongly agreed. From these data, we can infer that seminar is subjectively much more effective than lecture in clearing doubts.

Only $53.5 \%$ of students felt that seminar could cover wider aspect of topic while $95.4 \%$ opined that lecture covered wider aspect of topic, and of them, $53.5 \%$ of students strongly agreed. From these we can infer that lecture is subjectively more effective than seminar in covering wider aspect of topic.

$88.4 \%$ of students felt that seminar inspired them to learn further; but only $41.9 \%$ felt that lecture inspired to learn further. These data suggest that seminar is more effective than lecture in inspiring the students to learn further.

$93 \%$ of students opined that seminar helped in recollection of topic contents while only $51.1 \%$ students agreed that lecture helped in recollection of topic contents. From this, we can infer that seminar is more effective than lecture in improving the recollection of topic contents.

$86 \%$ of students felt that seminar would improve their performance in examinations while only $51.2 \%$ felt lecture would improve performance in examinations. So, seminar is felt by the students to be more effective than lecture in improving the performance of students in examinations.

$79.1 \%$ of students felt seminar to be interesting, but only $34.9 \%$ felt lecture to be interesting. So, for students, seminar is more interesting than lecture.

The researcher had asked the students to learn the topic by themselves in advance for the seminar, but did not ask the same for lecture. The researcher allotted greater class time for seminar than for lecture. So, total time spent by students 
for seminar was more than that spent for lecture. But, 55.8\% of students felt that lecture is a time-consuming method while $32.6 \%$ disagreed. Only $27.9 \%$ felt seminar to be time consuming while $30.3 \%$ disagreed. From these facts, we may infer that the time spent for seminar was more rewarding to the students than the time spent in attending the lecture, indicating that seminar is subjectively more effective than lecture in making use of the time spent.

$76.7 \%$ of students agreed that lecture helped in learning recent advances while only $51.2 \%$ agreed the same with seminar. This indicates that lecture is more effective than seminar in learning recent advances.

$74.4 \%$ of students opined that lecture would help in healthcare application while only $62.8 \%$ agreed the same with seminar. This indicates that though lecture as well as seminar helps in healthcare application, lecture may be more helpful in this aspect.

$76.7 \%$ of students felt seminar to be a better teachinglearning method while only $32.6 \%$ felt the same with lecture. So, seminar is subjectively a much more effective teachinglearning method than lecture. The above results regarding students' perceptions can be summarised as below:

\begin{tabular}{|c|c|c|c|}
\hline \multicolumn{4}{|c|}{ Seminar } \\
\hline Opinion & $\%$ & Chi square & $\mathbf{p}$ \\
\hline $\begin{array}{l}\text { Evoked more interest } \\
\text { in the topic }\end{array}$ & 86.1 & 24.3 & $<0.001^{*}$ \\
\hline $\begin{array}{l}\text { Helped to understand } \\
\text { concepts better }\end{array}$ & 90.7 & 32.2 & $<0.001^{*}$ \\
\hline Helped to clear doubts & 93 & 28.8 & $<0.001^{*}$ \\
\hline Inspired to learn further & 88.4 & 23.7 & $<0.001^{*}$ \\
\hline $\begin{array}{l}\text { Better recollection } \\
\text { of topics }\end{array}$ & 93 & 35.2 & $<0.001^{*}$ \\
\hline $\begin{array}{l}\text { Improves performance } \\
\text { in examinations }\end{array}$ & 86 & 19.2 & $<0.001^{*}$ \\
\hline Interesting method & 79.1 & 21.4 & $<0.001^{*}$ \\
\hline $\begin{array}{l}\text { Better/more effective } \\
\text { teaching-learning } \\
\text { method }\end{array}$ & 76.7 & 20.8 & $<0.001^{*}$ \\
\hline \multicolumn{4}{|c|}{ Lecture } \\
\hline Opinion & $\%$ & Chi square & $\mathbf{P}$ \\
\hline $\begin{array}{c}\text { Wider aspect of topic } \\
\text { covered }\end{array}$ & 95.4 & 20.5 & $<0.001^{*}$ \\
\hline $\begin{array}{l}\text { Helps in learning recent } \\
\text { advances }\end{array}$ & 76.7 & 10.1 & $<0.039 *$ \\
\hline $\begin{array}{l}\text { Helps in healthcare } \\
\text { application }\end{array}$ & 74.4 & 1.58 & $<0.812 \dagger$ \\
\hline Time consuming method & 55.8 & 11.8 & $0.018^{*}$ \\
\hline
\end{tabular}

*Statistically significant.

†Statistically not significant.

\section{DISCUSSION}

Lewis Elton classified teaching/learning methods into 3 broad groups: mass-instruction methods, individualisedlearning methods and group-learning methods. ${ }^{4}$ These differ in terms of the basic mode of instruction, the role of the teacher and the role of the student.

Lecture is the most widely used method of teaching. Lecture is a large group teaching method or mass-instruction method in which information is presented orally to a class with a minimal amount of class participation. The present study showed a greater cognitive gain by lecture compared to that by seminar, though the difference was statistically insignificant. This supports the findings of earlier researchers. Lecture is inappropriate as all-purpose method, but it can serve many useful instructional functions. ${ }^{5}$ To accomplish lower-cognitive educational objectives, lecture can be used. ${ }^{4}$ In this study, the cognitive gain was assessed for the lower recall level by MCQs. A lecture can disseminate a great deal of information to a large audience in a relatively short time. It allows the instructor to precisely determine the aims, content, organisation, pace and direction of the knowledge delivery. Facts and ideas that have been logically organised can be concisely presented in rapid sequence. Lecture may be the most suitable method to provide students with an introduction to or overview of a particular area of the subject, or to deal with a key topic in the course. ${ }^{4}$ First MBBS students were quite new to the topics taught for research purpose. Lectures can be used to present information that would be difficult for the student to get in other ways, particularly if they do not have access to reference material. In the present study, students perceived that lecture was superior to seminar in covering wider aspects of the topic and in learning recent advances. By using lecture, the instructor can offer students with varied backgrounds a common understanding of essential principles and facts.

In the present study, student's opined that seminar is a better/more effective method and has satisfied them more than the lecture. These findings are also in accordance with those of most of the previous studies. Learning is best achieved if students participate actively in a friendly, relaxed atmosphere. One teaching method in which there is active learning by students is seminar. It is a more student-centred teaching-learning method than lecture. It requires active participation of the student in the learning process. A study by Miller CJ and co-workers has confirmed the supremacy of an active teaching-learning method over a passive method. They compared didactic lecture with engaging lecture in teaching physiology to the same cohort of 120 School of Dentistry DMD students, and found that engaging lectures led to higher scores in unit examinations, greater long-term retention of information as evidenced by higher scores in the final examination, increased perceived effectiveness, decrease in distractions during lecture, and increased confidence with the material. ${ }^{1}$ The study by Rathnakar U P and colleagues reported that even when the size of the class was small, if the teaching style was didactic lectures, the results were poorer as compared to the performance of the same small group of students when the teaching involved was interactive. Their study has also demonstrated the advantage of group inputs in studying the subject, as against individual efforts. ${ }^{2}$ Zuzana de Jong and co-workers confirmed that even when the teaching method involved active learning, students and professionals prefer small group learning (Small group tutorial in their study) to learning in a large group interactive seminar. $^{3}$ Small group learning methods differ in effectiveness and student preference. In a prospective interventional study carried out in the subject of Pharmacology at Bharati Vidyapeeth Deemed University Medical College, seminar was found to be less effective than tutorial and case study in increasing the MCQ test scores. ${ }^{6}$ In that study 2 students from each group presented the 2 parts 
of the topic and the presentation was followed by discussion by all the students in the group. The students perceived seminar as less interesting than case study and tutorial. Contrary to the observations by many Western researchers, Malhotra and team observed that both objective performance and subjective satisfaction of students improved much more after traditional didactic lecture than student-led seminar on a common topic. ${ }^{7}$ Based on their observation, they commented that unsupervised student-led seminars cannot be used as the primary teaching-learning method at undergraduate level in India, where mainstream school education is pedagogy-based and does not prepare students for andragogy or self-directed adult learning process. This may explain the comparatively less cognitive gain achieved by seminar in the present study. The greater cognitive gain by lecture and the differences in lecture and seminar in satisfying different aspects revealed by the present study suggests that lecture as well as seminar have to be used to obtain optimal outcomes. Effective medical education may require an appropriate blend of large group methods, small group methods, didactic lecture and active learning as can be deciphered from the results of the study by George C. Xakellis and co-workers which revealed that the combination of $\mathrm{CD}$ ROM didactic material and small group seminars were more effective than either methods alone. ${ }^{8}$

\section{CONCLUSION}

From these Interpretations of the Analysis of the Results of this Study, we can make the following Concluding Inferences-

1. Seminar is subjectively more satisfying to the learners than lecture.

2. Seminar, compared to lecture, exerts greater prompting effect on the students to learn more on the topic later.

3. But immediate gain in recall-level knowledge during the preclinical phase of study on recent advances, wider aspect of topic and healthcare application are more imparted by lecture than by seminar, probably because of 'spoon feeding' of the knowledge the lecturer has gathered from various sources over time.

4. Any extra time required for seminar when compared to lecture is not a loss, because the additional knowledge imparted per unit time by seminar overwhelms the effect of the additional time spent.

5. Lecture as well as seminar is effective in causing cognitive gain; in this respect, both methods are almost equally effective.

6. Pre-existing knowledge on the topic is an important determinant of the knowledge gain from seminar.

At present, first year MBBS Physiology allots only much less hours of seminars compared to lectures. So, the advantages of seminars on learning are less available to students. For more effective teaching, the existing convention of mostly lectures and much less seminars needs to be replaced by allotting sufficient number of hours for seminars also to avail its advantages.
The present study has limitations in that it has not assessed the impacts of these teaching-learning methods on higher levels of cognition using questions other than MCQs, the longterm impacts, and the applicability of the findings to other different topics in Physiology. The cognitive gain and satisfaction obtained by lecture will depend also on the quality of the lecture delivered and hence the teaching skill of the teacher which was not considered in this study.

\section{REFERENCES}

[1] Miller CJ, McNear J, Metz MJ. A comparison of traditional and engaging lecture methods in a large, professional-level course. Advances in Physiology Education 2013;37(4):347-55.

http://www.ncbi.nlm.nih.gov/ pubmed/242929122.

[2] Rathnakar UP, Gopalakrishna HN, Pai PG, et al. Didactic lectures and interactive sessions in small groups: a comparative study among undergraduate students of pharmacology in India. Journal of Clinical and Diagnostic Research 2010;4(2):2260-4. http://www.jcdr.net/article_fulltext.asp?issn=0973$709 x \& y e a r=2010$ \&month $=$ April\&issue $=2 \& i d=6793$.

[3] de Jong Z, van Nies, Peters SW, et al. Interactive seminars or small group tutorials in preclinical medical education: results of a randomized controlled trial. BMC Medical Education 2010;10:79. http://www. biomed central.com/1472-6920/10/79.

[4] Earl S, McConnell M, Middleton I. Postgraduate certificate in tertiary level teaching. Aberdeen: The Robert Gordon University, Educational \& Staff Development Section, Centre for the Enhancement of Learning \& Teaching. 1998.

www2.rgu.ac.uk/celt/pgcerttlt/.

[5] Kaur G. Study and analysis of lecture model of teaching. International Journal of Educational Planning \& Administration 2011;1(1):9-13. http://www. ripublication.com/ijepa. htm

[6] Dawane JS, Pandit VA, Dhande PP, et al. A comparative study of different teaching methodologies used for developing understanding of Cardiac Pharmacology in undergraduate medical students. Journal of Research \& Method in Education 2014;4(3):Ver. III: 348.http://www.iosrjournals.org/iosr-jrme/papers/Vol4\%20Issue-3/Version-3/G04333438.pdf

[7] Malhotra, Pulkit, Khati, et al. Comparison of didactic lecture versus student led seminar as a tool for teaching - learning activity in an undergraduate medical college in India. Australasian Medical Journal 2013;6(4):216. http://connection.ebscohost.com/c/ abstracts/ 93330883/comparison-didactic-lectureversus-student-led-seminar-as-tool-teaching-learningactivity-undergraduate-medical-college-india

[8] Xakellis GC, Rickner S, Stevenson F. Comparison of knowledge acquired by students in small-group seminars with and without a formal didactic component. Fam Med 2005;37(1):27-9.

http://www.stfm.org/ fmhub/fm2005/ January/ George27.pdf 